\title{
Flood Alert System Using Sensor Networks in Flood Prone Zone
}

\author{
Luz Estella Torres Molina, $\mathrm{PhD}^{1}$, Idalides Vergara, $\mathrm{PhD}^{2}, \mathrm{H}$ Baez, $\mathrm{BEE}^{3}$ \\ ${ }^{1}$ Universidad del Turabo, Puerto Rico,TORRESL6@suagm.edu \\ ${ }^{2}$ Universidad del Turabo, Puerto Rico, ivergara@suagm.edu \\ ${ }^{3}$ Universidad del Turabo, Puerto Rico, hbaez2@email.suagm.edu
}

\begin{abstract}
Floods are one of the most costly natural disasters in the world and represent a common hazard in Puerto Rico. Floods can be local, impacting neighborhoods and communities, or large scale, impacting regions or the entire Island. Some floods develop slowly, sometimes over a period of a day or more. But flash floods can develop quickly, sometimes in just a few minutes and without any visible signs of rain. The uses of new technologies, such as a sensor network in parking lots connected to mobile phones that can determine the specific level of flooding, are important for prevention or for flood forecasting efforts and for mitigate the damage caused by this natural hazard. This project provides a real-time system able to monitor sudden floods in parking lots, streets or avenues; creating a personal opt-in alert that could reach an end user through their mobile phone. The system includes a wireless sensor network in which the sensor nodes are responsible for monitoring the water level using hydrostatic pressure sensors, and the sink node is responsible for sending the received data from the sensor nodes to a remote server via mobile communications network (GSM). Keywords-Floods, parking lots, SMS
\end{abstract}

\section{INTRODUCTION}

For the past ten years in Puerto Rico has increased the research in precipitation forecast, flood alert systems and disaster risk reduction. [1]. Floods are the most frequent disaster type and cause more humanitarian needs than other natural disasters. The use of new technologies with higher accuracy and covering areas missed by the radars, are important for flood warning systems efforts, and for studying and predicting atmospheric phenomena.

Currently, the National weather services in Puerto Rico has not any equipment available that has the capability to measure flow depth in real time and send this information by text message. It is needed because of the high potential for flooding in certain areas (e. g., in flood plains near the principal rivers of the region, parking lots, flood prone areas or hurricane prone areas such as Puerto Rico).

The Universidad del Turabo is developing a real-time flood detection system that alerts people thru text messages (SMS). The alert system will be able to monitor sudden flooding in prone areas to floods caused by overflowing rivers, extreme rainfall events, tropical storms or hurricanes, some of which fail to be detected by the only NEXRAD (WSR-88D) radar on the island, located at Cayey (Puerto Rico) and partially obstructed by mountains.
The system can be defined to have two main components, a Wireless Network Sensor (WSN) and a central server. The WSN will monitor flood levels in the area of interest and send the gathered data to the server which will analyze and store the data, register and handle the user data and send the corresponding alerts depending on the data received from the sensors. The system aims to have full compatibility with any mobile phone by using SMS text alerts.

The WSN needs to be installed in outdoor spaces where the power grid is not accessible in some cases. Therefore, each node received energy from solar radiation and work off the power grid when it is not available. In the WSN are defined two node types: sensing nodes, responsible for measuring water level using a hydrostatic pressure sensor and sending these data to the sink node which is responsible for gathering data from sensing nodes and sending these data to the central server.

There is worth to notice that in energy consumption is the major constraint in a WSN due to it runs off the power grid. In addition, the major energy consuming process is the wireless transmission between nodes. This problem was addressed by using synchronous sleep cycles for the sensing nodes in order to achieve a balance between rates of discharge versus the charge rate provided by the solar panel. With this approach, the system may theoretically work powered by a lithium ion 1.2Ah battery without taking into account the solar charging during two days.

Using this flood detection systems ensure: early and accurate flood detection, reduce loss of life, reduce damage to salvageable goods, additional evacuation time, lower infection rates from waterborne bacteria and lower insurance premiums.

\section{FLOODING AREA}

Coastal regions, especially islands such as Puerto Rico, frequently experience atmospherics phenomena that lead to flooding. The USGS has developed the Real Time Flood Alert System (RTFAS) for Puerto Rico [2]. RTFAS is a web-based computer program, developed as a data integration tool, and designed to assist emergency managers to predict flooding of streams in Puerto Rico.

It should be noted that the system is limited to providing stage elevation data at the locations of the USGS stream gauges RTFAS was available online at the following URL: (Real Time Flood Alert System - http://rtfas.er.usgs.gov/), but due to

Digital Object Identifier (DOI): http://dx.doi.org/10.18687/LACCEI2018.1.1.251 ISBN: 978-0-9993443-1-6

ISSN: $2414-6390$

$16^{\text {th }}$ LACCEI International Multi-Conference for Engineering, Education, and Technology: "Innovation in Education and Inclusion", 19-21 July 2018, Lima, Peru. 
lack of funding this system and website has been temporarily shut down. The National Weather Service (NWS) establishes Flash Flood Guidance estimates in real time based on the Sacramento soil moisture accounting model [3; 4]. The analysis allows for the development of curves that relate threshold runoff to flash flooding. Unfortunately, the model has not been successfully implemented in all of the island's watersheds.

For example, the model is incapable of producing accurate results in some of the watersheds of southeastern Puerto Rico, perhaps owning to the fact that some streams in this area loose significant amount of their flow to the underlying superficial aquifers [5]. According the U.S. Census Bureau at least $20 \%$ of habitant of the towns around the island lives in prone flood areas (e.g., the Puerto Rico western area has 3 important municipalities Mayagüez, Añasco and Cabo Rojo, see Fig. \# $1)$.

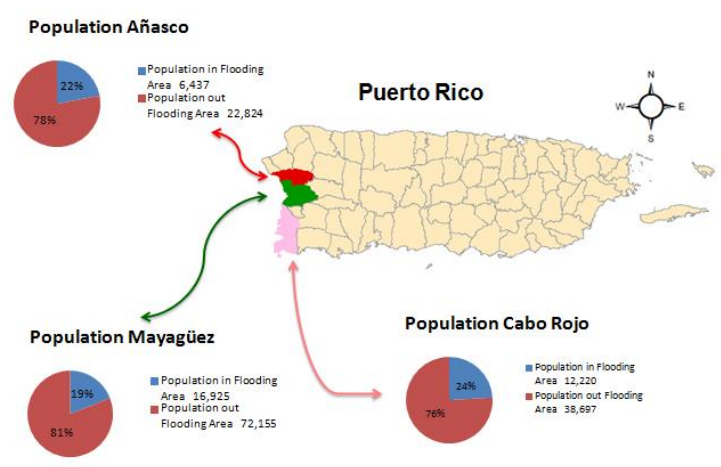

Fig. 1 Population lives in floodable areas, U.S. Census Bureau, 2010.

One of the largest and most important watersheds in Puerto Rico is the basin of the Río Grande de Añasco, see Fig \#2.

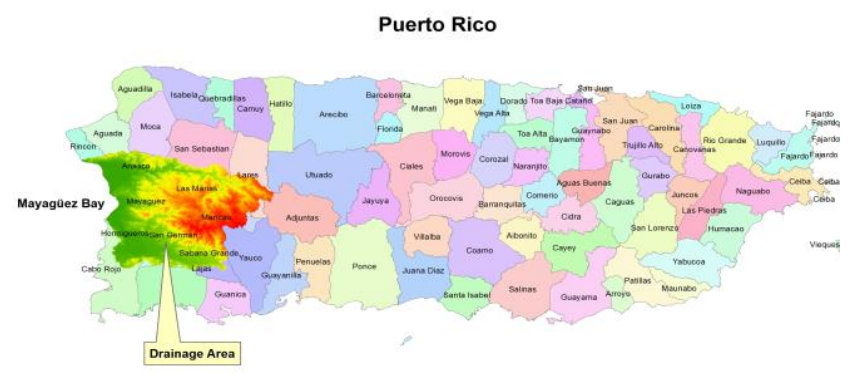

Fig. 2 Basin area location.

This basin has an area of $467.7 \mathrm{~km} 2$ of which approximately 10 percent of the area is flat land and the other remaining 90 percent is mountainous.

The floodplain covers approximately three-fourths of the flat land, and the residential developments in the Añasco municipality are partially within this area, and therefore can be affected by flooding.
Río Grande de Añasco flows westerly $74 \mathrm{~km}$ to the coast where its discharges into the Bay of Mayagüez, changes in elevation are shown in Fig. \# 3 and vary from zero meters at mean sea level in the coastal areas to 960 meters in the mountainous areas.

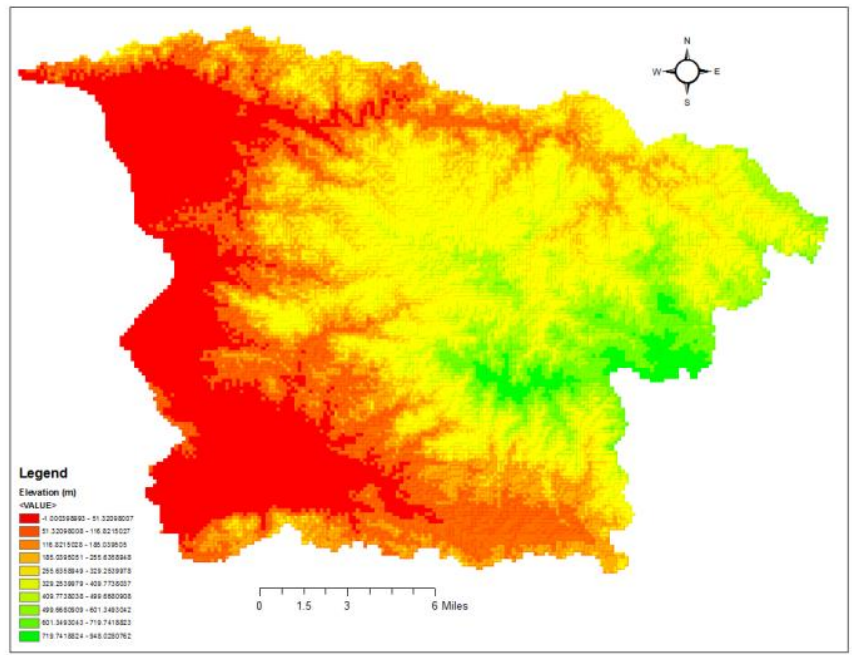

Fig. 3 Digital Elevation Model.

Flood problems in this study area are serious and widespread. Periodic flood damage to pastureland, roads, schools, parking lots and a number of residential areas is significant [1]. Some of the flooding events in the city of Mayaguez, Puerto Rico and the damage being made by flooding are show in Fig \# 4 and Fig \# 5. In this case flood water level rose faster and less time was given for the people for their evacuation in this parking lot there are not any system to early flood warning. The people around this location have to plans wisely and according to the rainfall change by them self's.

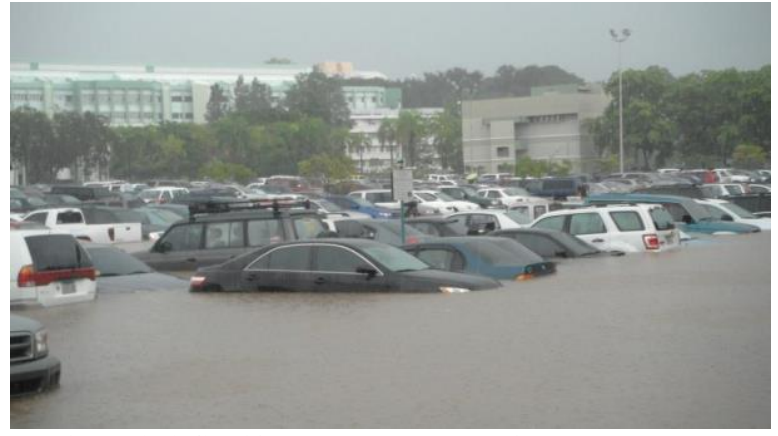

Fig. 4 Flash flood in Mayagüez, Puerto Rico (Sep 19, 2011).

The damage costs are elevated in Puerto Rico because there is a large population residing in floodplain regions, areas which have at least a $0.2 \%$ chance of flooding each year. An estimated 50,000 structures and 150,000 people are located in designated floodplains. Many of these residents live in low 
income housing built before government flood zone regulations were established [6].

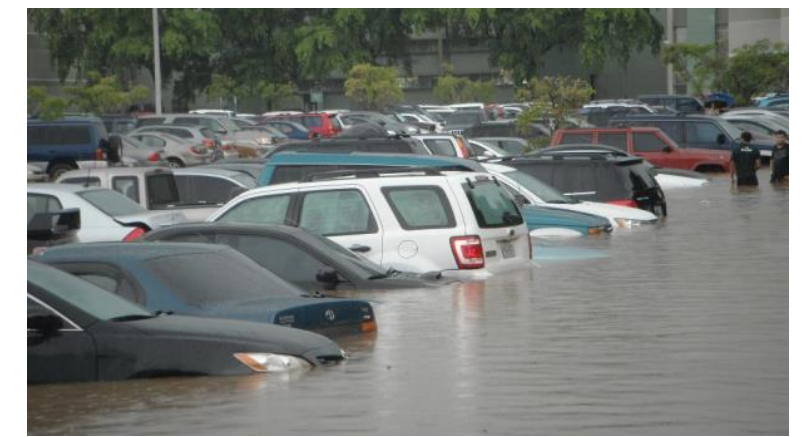

Fig. 5 Flash flood in parking lot Mayagüez, Puerto Rico (Sep 19, 2011).

The geographic location of Puerto Rico makes it suitable for Tropical weather; the past years have unleashed a series of precipitations that cause huge floods, destroying hundreds of homes, sweeping away cars and leaving thousands without power. On July 2013, San Juan PR received $36 \mathrm{~cm}$ of precipitation. More rain fell on July 18 than had ever come down in a 24-hour period with $23 \mathrm{~cm}$ pelting the San Juan area. People fled homes and cars as water rushed through doors and then windows. Rising floodwaters stranded drivers on highways turned lagoons. The precipitation severely damaged some 500 homes and caused about $\$ 1.5$ million in losses [7]. The Puerto Rico government spends large sum of money on repairing damage caused by flooding. The most frequent types of flooding in Puerto Rico are river flooding, flash flooding, and coastal flooding. The proposed system can be utilized as a flood warning system for these three types of floods present in Puerto Rico. The river flooding occurs when the discharge of water exceeds the river's banks and flows onto floodplains. Communities lying close to rivers and streams are most affected by river floods. The flash floods have rapid water velocity, sudden rise in water levels, and substantial amounts of debris [8]. The flash floods typically occur after long, intense amounts of rainfall in steeper areas such as parking lots, avenues, road and residential development on flooding areas. In a typical flash flood, the water velocity is about nine feet per second, which is strong enough to move objects weighing around 100 pounds and is equivalent to the damage caused by $270 \mathrm{mph}$ winds. Flash floods have the capability to destroy houses and roads, and kill people who may be in their paths, causing great destruction in the area established [6]. The last one is the coastal flooding, this cause severe damage along coasts, which is the result of wave actions. Puerto Rico has three types of coastal rocky cliffs and headlands, mangrove coast and sand or gravel beaches, the last one is the most affected by wave actions in some cases occurring erosion and loss of coast. The loss of coastal is optimal zone for flood by wave action.

\section{PUERTO RICO SOIL CLASSIFICATION}

Rainfall is the most important factor in creating a flood, but there are many other contributing factors. A portion of the rain that falls on a basin is captured by soil and vegetation. Usually the more rain that falls in a specific area in a given period of time, the lower the proportion that can seep into the ground or be stored on the surface. The more vegetation there is in an area, the greater the amount of rainfall that is captured and the less water there is available to flow over the surface and produce flooding. The soil classification and land use play a very large role in flood management. They control the amount of precipitation that can infiltrate into the soil, and hence the amount of rainfall which become flow. Commonly the people think of why an area is prone to flooding, they think of the topography area or terrain. Many people do not take into consideration the soil permeability. The Journal of Environmental Management included in their article on mapping flood hazard the three types of factors to strongly analyze to help flood management and prediction: "topography, soil type, and land use "and that "soil properties or soil classification "was definitely a main driver in flood recovery [9].

Soil permeability is an important property of soil classification and depends of the soil type, this affect quantity and velocity of water infiltration and how much an area can flood, but also the recovery time of an area after a flood event. The Permeability varies according to soil texture, usually the finer the soil texture, the slower the permeability. Puerto Rico has a wide range of textures ranging from fine texture such as clayey soils to coarse texture such as sandy soils. A representative soil of Puerto Rico is the Bayamon Soil. The Bayamon series consists of very deep, very slowly permeable soils on coastal plains with texture very fine and an elevate percentage of clay [10]. A portion of Puerto Rico was analyzed, using a soil map provided by United States Department of Agriculture - Natural Resources Conservation service (USDA-NRCS). The soil textures present in this study as percent of area are clay with $62.49 \%$, clay-loam $24.96 \%$, rock $8.69 \%$, loam $3.00 \%$, sand $0.81 \%$ and gravel $0.04 \%$. A soil map describing the class distribution is necessary to assign the values the Green-Ampt infiltration parameters, see Fig \# 6 . 


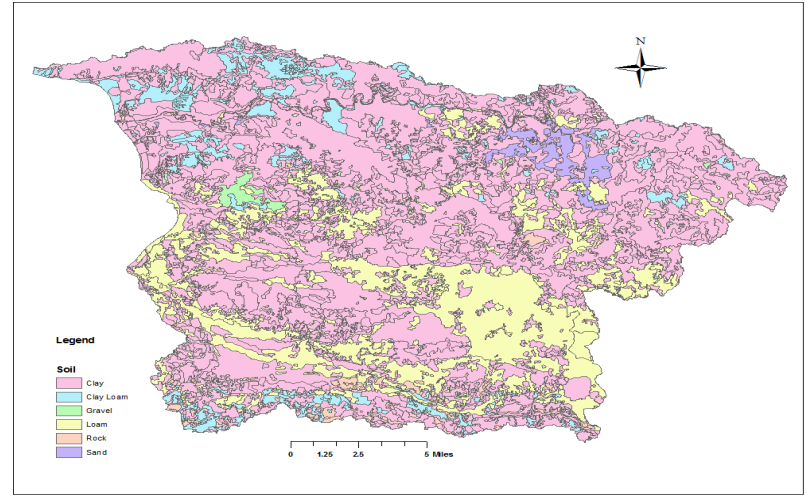

Fig. 6 Soil Present in the representative area. [Source: Soil Survey Geographic (SSURGO)].

With a higher percentage of soil clay, it is possible to observe that the selected area is a representative portion of Puerto Rico soil classification. Fig \# 7 presents the percent of texture into the representative basin area, in which the clay encompasses most the basin area with $62.4 \%$ of total area. On the other hand the minimum texture present in the basin is the Gravel with a value approximate to $0.02 \%$. The soil classification or texture has a direct relationship with the hydraulic conductivity, it is a measure of permeability, it can generally be concluded that rocks and sediments with large pore space will have larger hydraulic conductivities than those with very small pores such as clays. For this area clay with very small particles packed close together has a hydraulic conductivity of $0,03(\mathrm{~cm} / \mathrm{h})$. Sand, on the other hand, has a much large value of hydraulic conductivities of $11.78(\mathrm{~cm} / \mathrm{h})$.

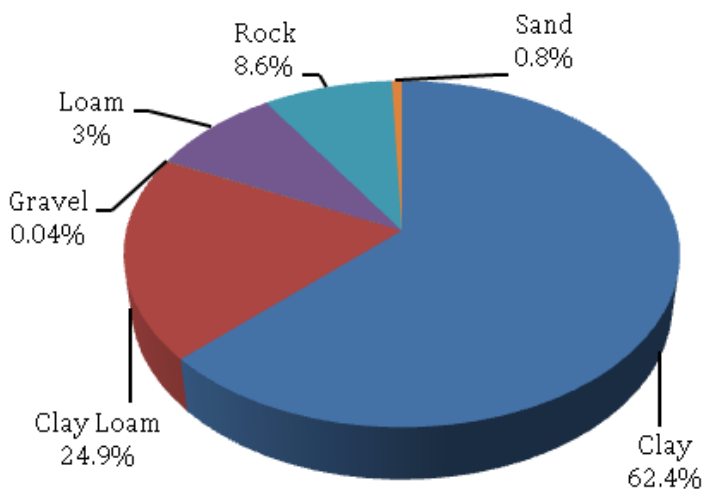

Fig. 7 Soil percent in the representative area

This representative area with high quantity of Clay has low permeability will be much more likely to flood versus a soil with a high permeability, because of its ability to infiltrate water more slowly, thus flooding at all or possessing a slow recovery rate.

\section{PUERTO Rico FloOd HAZARd ZoNe DESIGNATION}

The last years in Puerto Rico the construction of areas that cannot absorb water, such as roads, avenues, and parking lots have increased and they will also result in reduced infiltration and more rainfall being turned into runoff producing flooding. Most land classified by FEMA as having a high risk of flooding (presumable on the basis of elevation, slope and proximity to water) tend to have soils with poor internal drainage. Using the FEMA data was determined the 100-year flood zone in Puerto Rico, see Fig \# 8.

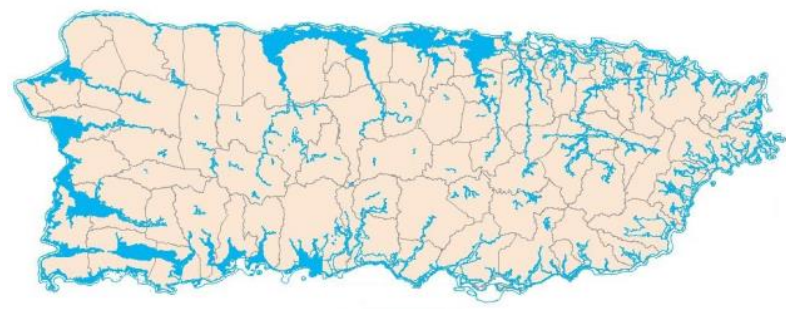

Fig. 8 Puerto Rico 100-year flood zone

Recently, the Commonwealth of Puerto Rico estimates the chances of flooding in a determined area by using Flood Insurance Rate Maps (FIRMs). The maps utilize Geographic Information System (GIS) to know historical flood data and hydrological data to map floodplains according to specific risk designations. There is several different risk designations associated with FIRMs. The major differentiation for flood zones is generated using the frequency of flooding. 100-year flood zones are likely to have $1 \%$ annual chance of flooding or a $26 \%$ chance of flooding during a thirty year mortgage. The planning Board of Puerto Rico is the local agency designated to be responsible for flood management around the island. In January 2010, this agency put into effect the "Special Flood Hazard Areas regulation" to provide more stringent measures on building within designated flood zones. No new structures may be built on floodways, actually there is much infrastructure located in floodplains that can still suffer damage from flooding

\section{THE PROPOSED SYSTEM}

This paper presents a real-time monitoring system for parking lots. The proposed system includes a Wireless Sensor Network (WSN) connected via Internet to a central infrastructure for data processing and alerting procedure. The main idea is to sensor the flooding level at a parking lot using the WSN. The collected data is reported to the central infrastructure. When a flooding threshold is reached, the server alerts the registered users via text message (SMS) as shown in Fig \# 9.

$16^{\text {th }}$ LACCEI International Multi-Conference for Engineering, Education, and Technology: "Innovation in Education and 


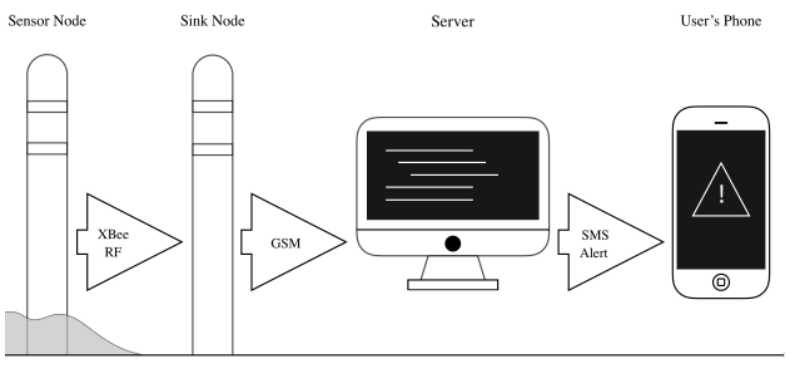

Fig. 9 Basic system design.

\section{A. Wireless Sensor Network Architecture}

A traditional WSN defines a set of sensor nodes and a central sink node. The sensor nodes are responsible for collecting data and reporting them to the sink node. This sink node performs an initial data aggregation process, these aggregated data are sent to a server for data analysis, decision making processes.

In this project, the sensor nodes sense flood level using a Milone eTape liquid level sensor which is a hydrostatic pressure level sensor, and changes its resistive output depending on the external pressure applied by the liquid. The Milone eTape is connected to as Arduino UNO R3 micro controller unit (MCU) which digitalized the sensor resistive and convert it into inches. Finally, the MCU is connected to a data transmitter (i.e., 2.4GHz XBee Series 1 module (XB24DMWIT-250)) which is used to send data to the sink node. Fig \# 10 shows the sensor nodes architecture. It is important to take into consideration that sensor nodes will be powered by the electrical grid when available. However, these nodes are designed to be powered and charged using a 10W Polycrystalline solar panel with a $1200 \mathrm{mAh}$ rechargeable battery pack for locations where the electrical grid is not available.
10W Polycrystalline Solar Module

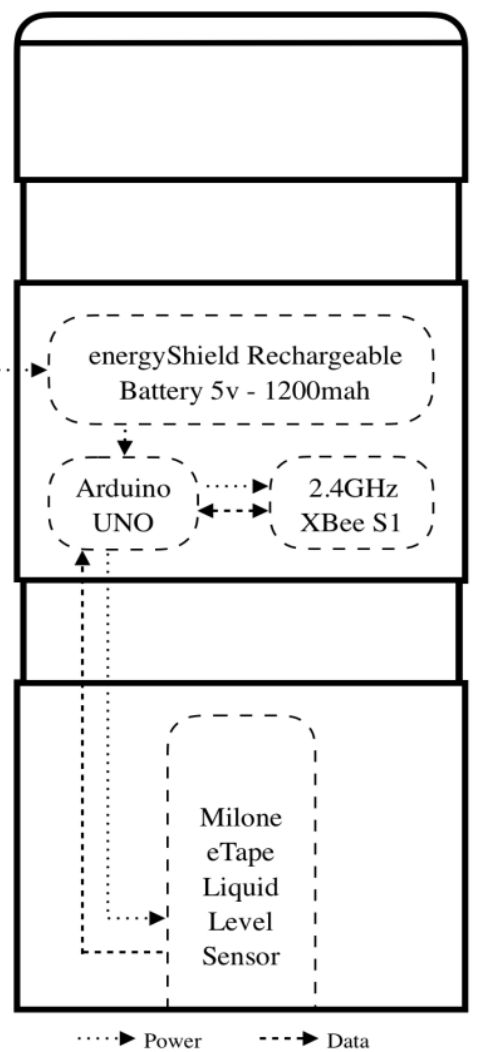

Fig. 10 Sensor node architecture.

The sink node performs the data collection from sensor nodes, and performs the initial data aggregation. This nodes uses an Arduino MEGA 2560 for data processing connected to an XBee module (XB24-DMWIT-250) for receiving data from sensor nodes. In addition, the sink node uses GSM communication for reporting the collected data to the central server via Internet. Fig \# 11 shows the sink node architecture

$16^{\text {th }}$ LACCEI International Multi-Conference for Engineering, Education, and Technology: "Innovation in Education and 


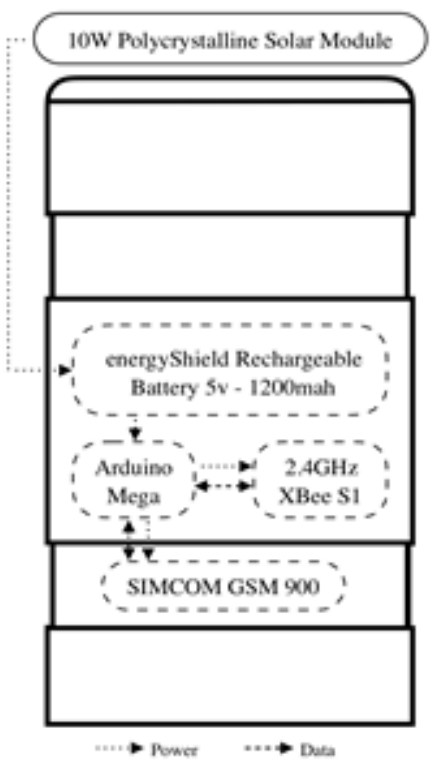

Fig. 11 Sink node architecture.

\section{B. Data Processing and Alert Protocol}

Once the sink node receives data from sensor network, it performs an initial data aggregation. These aggregated data is reported to a server for data processing, and decision making process. Take into consideration that this server is designed to manage multiple networks located in different locations.

The server stores the received data, processes the reported level from each WSN, verifies users in each area, and alerts users when a flooding threshold is reached as showed in fig \# 12.

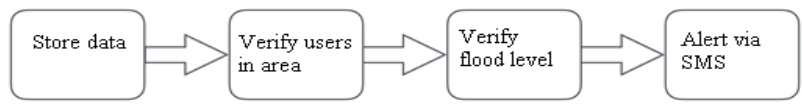

Fig. 12 Server actions upon arrival of data.

\section{User Registration}

In order to receive an alert when required, the users must be register in the system once they get in the parking lot. User needs to send a text message with the parking area to telephone number showed in the parking lot. Registered users will be kept on the database for a total of 12 hours before being removed from the alert service. When a flooding threshold is reached, the system will alert registered users via SMS. This mechanism does not require users to have a smartphone. The SMS technology guarantees message compatibility with any cellphone in the market.

\section{Communication Protocol and Power Management}

The major constraint in Wireless Sensor Networks is the power consumption, particularly, due to data transmission. The larger the distance between sensor nodes and sink node, the faster the battery is discharged. In order to optimize the battery use, this project uses the DigiMesh networking protocol, a proprietary protocol based on a modified version of the AODV (Ad-Hoc on Demand Distance Vector) routing algorithm [11]. This means that each sensor node is a router allowing each sensor network to send data to its closest neighbor and so on until reach the sink node. The selected radios implement the protocol, and provide a low latency as well as predictable communication timing according with [13]. In addition, the use of a mesh network for the system improves the network reliability given the fact that it will recompute another route in case of a node failure [14]. Fig \# 13 shows the WSN topology in which $\mathrm{R}$ represents a sensor node running the DigiMesh protocol.

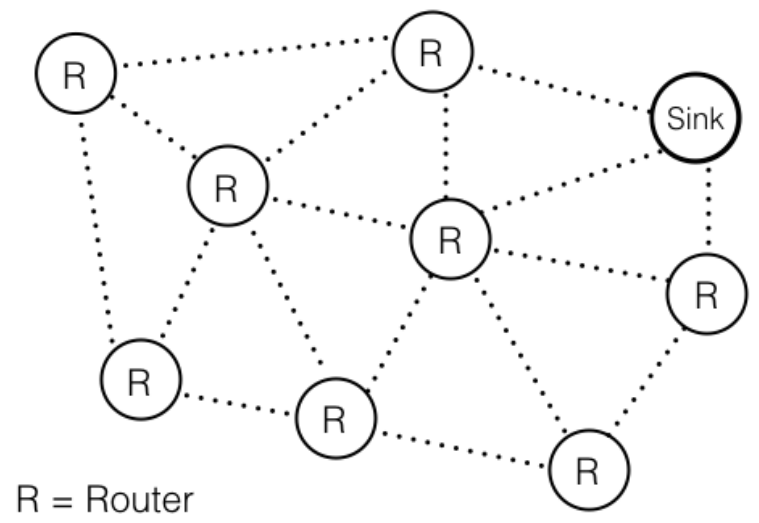

Fig. 13 DigiMesh network topology.

As stated before, the major power consumption WSN is due to data transmission. In order to reduce power consumption, this project defines a Sleep-Transmission cycle in the WSN shown in algorithm 1 . The cycle chosen will have the network waking up for 2 seconds every 3 minutes. During the Transmission state, each sensor node sends and route the data to the closest neighbor until reach the sink node. Then, the WSN does not transmit for three minutes. And, it transmits for 2 seconds and so on. In this scheme, the whole network wakeup is then managed by a set Sleep coordinator (i.e., the Sink node). The coordinator controls the timing of the other radios by sending a control message notifying if they are off schedule keeping the network in a synchronous state. By having the radios control the sleep cycle, we avoid having to add additional clock circuitry to the Arduino node by just waking it up via pin interrupt on pin 2. When the Arduino wakes up, it senses and processes the data and sends it to the sink node. After a small delay it goes into powered down sleep.

16 $^{\text {th }}$ LACCEI International Multi-Conference for Engineering, Education, and Technology: "Innovation in Education and Inclusion", 19-21 July 2018, Lima, Peru. 
TABLE 1.

AlgORITHM 1 SENSOR NODE PROGRAM

\begin{tabular}{|ll|}
\hline 1: & Initialize \\
2: & while true do \\
3: & sensor $\mathrm{V}$ al $\leftarrow(1023 /$ analog Read $)-1$ \\
$4:$ & res $\leftarrow($ ref RES/ sensorV al $)$ \\
5: & payload $\leftarrow$ res \\
6: & Create a Transmit Packet with updated payload \\
7: & Send TX Packet to the sink \\
8: & Sleep for 3 minutes \\
9: & End while \\
\hline
\end{tabular}

\section{PERFORMANCE EVALUATION}

An alert system is as reliable as it is available to alert when required. Therefore, the major aspects to observe are the power consumption, given the power constraint associated with WSN, and the communication performance.

\section{A. Power Consumption}

Since sensor nodes may be located out of the electrical grid, it is very important to measure the energy consumption in order to establish the appropriate system availability. In this section, the power consumption of each sensor node was measured according to the following methodology:

The sensor node's current consumption was measured in both active and sleeping states to determine the average hourly current consumption. The key variables for this are the following:

- Ia - Current while awake

- Is - Current while sleeping

- Sa - Seconds spent awake

- F - Sensor cycle frequency

The sensor node consumes $83.7 \mathrm{~mA}$ while sensing (Ia) and $22.3 \mathrm{~mA}$ when sleeping (Is).

The cycle used was of 2 seconds of activity (Sa) and 3 minutes of sleep (F). With these values we could determine the hourly average in the following manner:

$$
\text { AvgCurrent }=\frac{\left(I a \cdot S_{a}+I s \cdot\left(F-S_{a}\right)\right)}{F}
$$

From this, an hourly average current consumption of $23.9 \mathrm{~mA}$ was obtained. Using a $1200 \mathrm{mAh}$ battery, that gives us around 52.4 hours of autonomous operation.

\section{B. Communication Performance}

A key aspect in the communication performances is the distance between sensor nodes and the packet delivery ratio (i.e., percentage of successfully delivered packets). The distance between nodes are crucial in a WSN because the longer distance between nodes, the faster the battery is discharged since the radio needs more power in order to reach the neighboring node. However, the system requires to be balanced respect the number of sensor nodes and the power consumption.

In order to determine the relation between distance and packet delivery ratio, we ran packet delivery tests using the XCTU (i.e., an application for the configuration and testing of the XBee radios). We looked to get a high enough delivery rate as to avoid the packet retransmission. Since the network is in a synchronized sleep cycle, the message might not reach the destination as it might run the risk of the network going to sleep during its route.

Based on fig \# 14, 9.15m achieves a 97\% of packets delivered when there is not a line of sight between each other sensor nodes. The relation between packet delivery ratio and distance between nodes is heavily dependent on external factors such as line of sight and channel congestion. With line of sight, the XBee radios used should be able to have close to 30 meters of range in urban areas.

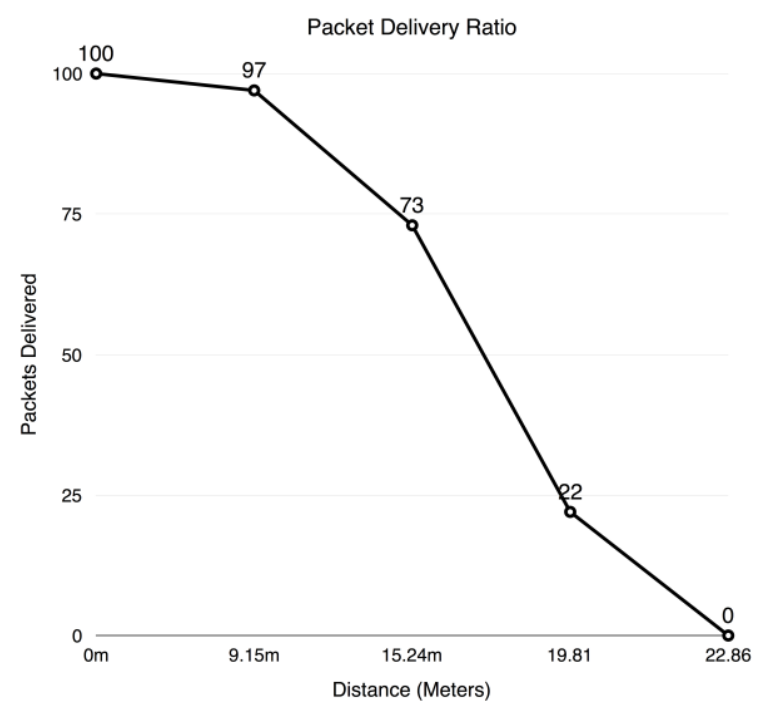

Fig. 14 Packet delivery test results.

$16^{\text {th }}$ LACCEI International Multi-Conference for Engineering, Education, and Technology: "Innovation in Education and Inclusion”, 19-21 July 2018, Lima, Peru. 


\section{CONCLUSION}

This paper represents the first time that water level technology has been used for hydrologic analyses and specifically for flood alert system in parking lots in Puerto Rico.

In this research were studied the hydrologic parameters that can affect or increase the flood in Puerto Rico. Based on analyses and GIS data was found that the soil texture and land used are the most hydrological sensitive parameter, but the increase of impervious area an poor urban planning in the last years has been the causing of the increase in flood. The hydrological parameters were evaluates in this study within a relative small area, approximately $1 / 10$ of the total area of Puerto Rico.

The proposed system sends flood SMS alerts to the inhabitant of such zones for necessary action. The flood monitoring system can be expanded to cover a wider area than the one under study due to the DigiMesh protocol capabilities. In addition, this model can be used in flash flood, parking lots, street prone to flooding and other zone with high probability to flood.

\section{REFERENCES}

[1] Torres-Molina, L.E., (2014). Flood Alert system Using Rainfall Data in The Mayagüez Bay Drainage Basin, Western Puerto Rico. Doctor of Philosophy in Civil Engineering, University of Puerto Rico at Mayagüez, PR.

[2] USGS, (2010). Real Time Flood Alert System (RTFAS) for Puerto Rico. Fact Sheet 2010-3029, May.

[3] Georgakakos, K.P., (2006). Analytical results for operational flash flood guidance. Journal of Hydrology, 317, 81-103.

[4] Burnash, R.J.C., R.L. Ferral, and R.A. McGuire (1973). A generalized streamflow simulation system-Conceptual modeling for digital computers. Tech. Rep. to the Joint Federal and State River Forecast Center, U.S. National Weather Service and California Department of Water Resources, Sacramento, 204 pp

[5] Diaz Gonzalez, M.F., (2012). Estimation of Water Balance and Groundwater Processes of the Salinas to Patillas Area in Southeastern Puerto Rico for 1980-2010. Master's Thesis. Department of Civil Engineering, University of Puerto Rico - Mayagüez Campus. Pp. 177.

[6] Mues, L., Heckley, C., Reis, A., \& Taylor, H. Estimating Floodplain Populations and Assessing Flood Risk and Flood Mitigation in Puerto Rico.

[7] WeatherFanatics- http://weatherfanatics.blogspot.com/2013/08/puertorico-drenched-by-tropical-rains.html.

[8] Wright, J.M. (2008). Chapter 2: Floodplain Management. Manuscript submitted for publication, University of Tennessee, Knoxville, TN. Retrieved on January 28, 2011, from http://training.fema.gov/EMIWeb/edu/docs/fmpcp/Chapter\%202\%20$\% 20$ Types\%20of\%20Floods\%20adn\%20Floodplains.pdf.

[9] Kalantari, Zahra , Alireza Nickman, Steve W. Lyon, Bo Olofsson, and Lennart Folkeson. "A Method for Mapping Flood Hazard Along Roads." Journal of Environmental Management 133 (2014): 69-77. Print.

[10] Natural Resources Conservation Servicehttps://www.nrcs.usda.gov/wps/portal/nrcs/surveylist/soils/survey/ state/?stateId=PR

[11] C. E. Perkins and E. M. Royer, "Ad-hoc on-demand distance vector routing," tech. rep., 2003.

[12] "Wireless mesh networking white paper - zigbee vs. digimesh," tech. rep., 2015.
[13] V. Khedekar, "A review on xbee technology," International Journal of Emerging Technologies in Engineering Research, vol. 4, no. 4, 2016.

[14] V. Mayalarp, N. Limpaswadpaisarn, T. Poombansao, and S. Kittipiyakul, "Wireless mesh networking with xbee," ResearchGate, 10 2014.

[15] R. Faludi, Building Wireless Sensor Networks - A Practical Guide to the ZigBee Networking Protocol. United States: O'Reilly, 1st ed., 012012.

[16] S. Saxena, S. Mishra, A. Kumar, and S. Chauhan, "Efficient power utilization techniques for wireless sensor networks - a survey," International Journal on Computer Science and Engineering (IJCSE), vol. 3, pp. 905 - 925, 022011.

[17] "Designing a sleeping xbee sensor - digi developer," 2011.

$16^{\text {th }}$ LACCEI International Multi-Conference for Engineering, Education, and Technology: "Innovation in Education and Inclusion", 19-21 July 2018, Lima, Peru. 